\title{
Pyridoxal 5'-Phosphate Modulates Expression of Cytosolic Aspartate Aminotransferase Gene by Inactivation of Glucocorticoid Receptor
}

\author{
Tatsuzo OKA*, Naomi Komori, Masashi Kuwahata, Yuzo Hiroi, ${ }^{1}$ \\ Taeko ShIMOdA, ${ }^{2}$ Mitsuko OKADA, ${ }^{3}$ and Yasuo NATORI \\ Department of Nutritional Chemistry, School of Medicine, \\ The University of Tokushima, Tokushima 770, Japan \\ ${ }^{1}$ Department of Food and Nutrition, Nakamura Gakuen College, \\ Fukuoka 814, Japan \\ ${ }^{2}$ Faculty of Home Economics, Kyushu Women's University, \\ Kitakyushu 870, Japan \\ ${ }^{3}$ Faculty of Health and Living Science, Naruto University of \\ Education, Naruto 772, Japan \\ (Received January 20, 1995)
}

\begin{abstract}
Summary The level of mRNA for cytosolic aspartate aminotransferase (cAST) in the liver of vitamin $\mathrm{B}_{6}$-deficient rats was found to be 7-fold higher than that of the control rats. The administration of hydrocortisone to adrenalectomized vitamin $\mathrm{B}_{6}$-deficient rats induced expression of hepatic cAST mRNA and the induction was suppressed by the simultaneous administration of pyridoxine. Since the $5^{\prime}$ regulatory region of the rat cAST gene contains several sequences showing homology to glucocorticoid-responsive elements, we synthesized an oligonucleotide probe of glucocorticoid-responsive element sequence and assayed the binding activity of liver nuclear extract to the oligonucleotide by gel mobility shift analysis. We found that the binding activity of nuclear extract prepared from the liver of vitamin $\mathbf{B}_{6}$-deficient rats was far greater than that of the control rats, indicating that the DNA-binding activity of glucocorticoid receptor was enhanced by vitamin $B_{6}$ deficiency. We further found that preincubation of the nuclear extract from the vitamin-deficient liver with pyridoxal $5^{\prime}$-phosphate brought about a rapid and extensive decrease in the binding of the extract to the glucocorticoid-responsive element. Congeners of pyridoxal phosphate, such as pyridoxamine $5^{\prime}$-phosphate, pyridoxal, pyridoxamine and pyridoxine, did not show an inhibitory effect. These observations suggest that pyridoxal $5^{\prime}$-phosphate modulates cAST gene expression by inactivating the binding activity of glucocorticoid receptor to glucocorticoid-responsive elements.
\end{abstract}

* To whom correspondence should be addressed. 
Key Words vitamin $\mathrm{B}_{6}$, aspartate aminotransferase, gene expression, glucocorticoid receptor, glucocorticoid-responsive element, rats

Aspartate aminotransferase (AST, EC 2.6.1.1) is a pyridoxal $5^{\prime}$-phosphate (PLP)-dependent enzyme which plays an important role in amino acid metabolism in various organisms. In animal cells, AST exists as two isozymes, one cytosolic (cAST) and the other mitochondrial (mAST) (1). Although cAST is present in all animal tissues, its hormonal regulation is tissue-specific; for instance, the administration of glucocorticoids to rats induces cAST in the liver and kidney but not in other tissues (2).

One interesting feature of enzyme induction by glucocorticoid hormone is that the induction is modulated by vitamin $B_{6}$. Since Cake et al. (3) found that PLP inhibits the binding of rat-liver glucocorticoid receptor to DNA-cellulose, several laboratories have attempted to establish a definitive correlation between vitamin $\mathrm{B}_{6}$ and steroid hormone action. DiSorbo and Litwack (4) have reported that incubation of rat hepatomas in a pyridoxine-free medium results in a decrease in the intracellular level of PLP and significant enhancement of the induction of tyrosine aminotransferase. Similarly, the work of Majumder et al. (5) has shown that increased concentrations of vitamin $\mathrm{B}_{6}$ inhibit glucocorticoid-induced casein messenger RNA accumulation in the mouse mammary gland. In a recent study, Allgood et al. (6) showed that vitamin $\mathrm{B}_{6}$ modulates transcriptional activation by the human glucocorticoid receptor in $\mathrm{HeLa} \mathrm{S}_{3}$ cells. Allgood and Cidlowski (7) have further reported that the modulatory effects of vitamin $B_{6}$ on transcriptional activation is not limited to glucocorticoid receptor but extends to multiple members of the steroid hormone receptor superfamily. However, the molecular mechanism through which vitamin $B_{6}$ modulates the interaction of the steroid-receptor complex with hormone regulatory or responsive elements of specific genes has not been elucidated.

In an earlier work in our laboratory, we demonstrated that the induction of cAST in the liver of adrenalectomized vitamin $\mathrm{B}_{6}$-deficient rats by hydrocortisone is suppressed by the administration of pyridoxine (8). In this manuscript, we provide evidence to suggest that PLP directly interacts with the glucocorticoid receptor and modulates cAST gene expression in the rat liver through a novel mechanism that involves inactivation of the glucocorticoid receptor.

\section{MATERIALS AND METHODS}

Animal treatment. Male Wistar rats, weighing about $50 \mathrm{~g}$, were given a $70 \%$ casein diet with or without pyridoxine ad libitum for 4 weeks. The composition of the diet was previously described (9). For experiments involving hydrocortisone treatment, rats were bilaterally adrenalectomized after feeding a pyridoxine-free diet for 3 weeks and the operated animals were thereafter maintained on $0.9 \%$ $\mathrm{NaCl}$ as drinking water. Treatment with hydrocortisone and/or pyridoxine was 
started 1 week after adrenalectomy, each rat receiving an intraperitoneal injection of hydrocortisone $(5 \mathrm{mg} / 100 \mathrm{~g}$ body weight $)$ and/or pyridoxine $(10 \mathrm{mg} / 100 \mathrm{~g}$ body weight) in isotonic saline daily for 4 days. Untreated rats received an injection of isotonic saline. Animals were killed by decapitation, and the livers were removed, immediately frozen in liquid nitrogen and then stored at $-80^{\circ} \mathrm{C}$ until the nuclei and RNA were prepared.

Northern blot hybridization. Total RNA was isolated from the liver and subjected to Northern blot hybridization using ${ }^{32} \mathrm{P}$-labeled rat liver cAST cDNA (gift of Dr. H. Wada, Osaka University, Osaka, Japan) as described previously (10). The intensity of autographic bands was quantitated using an LKB Ultro Scan Laser Densitometer and expressed as a percentage of control levels.

Slot blot analysis. Serial dilutions of total RNA were subjected to slot blot analysis using ${ }^{32} \mathrm{P}$-labeled cAST cDNA as described previously (10).

Gel mobility shift assay. Nuclear extracts were prepared from the livers essentially as described by Dignam et al. (11). The oligonucleotide used as a probe (GGTACAGCGTGTCCA) was the glucocorticoid-responsive element sequence found between positions -585 and -571 of the rat cAST gene (12). The probe was synthesized on an Applied Biosystems synthesizer and double-stranded oligonucleotide obtained by annealing was labeled with ${ }^{32} \mathrm{P}$ at the $5^{\prime}$ end by T4 polynucleotide kinase. Gel mobility shift assay was performed essentially as described by Chodosh (13) in $10 \mu \mathrm{l}$ containing up to $10 \mu \mathrm{g}$ of nuclear extract protein. Nuclear extracts were incubated with poly $(\mathrm{dI}-\mathrm{dC}) \cdot \operatorname{poly}(\mathrm{dI}-\mathrm{dC})$ in a binding buffer consisting of $10 \mathrm{mM}$ HEPES ( $\mathrm{pH} \mathrm{7.5),} 50 \mathrm{mM} \mathrm{KCl}, 2.5 \mathrm{mM} \mathrm{MgCl}_{2}$, $0.1 \mathrm{~mm}$ EDTA, $1 \mathrm{~mm}$ dithiothreitol, and $5 \%$ glycerol for $30 \mathrm{~min}$ at $25^{\circ} \mathrm{C}$, after which ${ }^{32} \mathrm{P}$-labeled oligonucleotide probe $(20,000 \mathrm{cpm}, 5 \mathrm{fmol})$ was added and the reactions incubated for $30 \mathrm{~min}$ at $25^{\circ} \mathrm{C}$. In some cases, 50- to 100 -fold unlabeled oligonucleotide was added to the reaction mixture. Reactions were analyzed on $5 \%$ polyacrylamide gels as described (13).

\section{RESULTS}

Hepatic cAST $m R N A$ level is elevated in vitamin $B_{6}$ deficiency

Rats were fed a $70 \%$ casein diet with or without pyridoxine ad libitum for 4 weeks. In previous study from our laboratory, we demonstrated that the content of PLP in the liver of rats fed the vitamin $\mathrm{B}_{6}$-deficient diet was reduced to approximately $15 \%$ of the rats fed the vitamin $\mathrm{B}_{6}$-containing control diet at the end of the feeding schedule (control, $12.3 \mathrm{nmol} / \mathrm{g}$ liver; $\mathbf{B}_{6}$-deficient, $1.8 \mathrm{nmol} / \mathrm{g}$ liver) (14). The total RNA isolated from the livers, was subjected to Northern blot analysis using a cAST cDNA probe. The autoradiograph revealed one major $(2.1 \mathrm{~kb})$ and one minor $(1.8 \mathrm{~kb})$ band, in agreement with the report of Pave-Preux et al. (2) (Fig. 1A). Estimation by densitometric tracing showed that the cAST mRNA level in the liver of vitamin $\mathrm{B}_{6}$-deficient rats was 7 -fold higher than that in the control rats. 
A

$$
\text { อ }
$$

\section{$2.1 \mathrm{kbr}$}

1.8

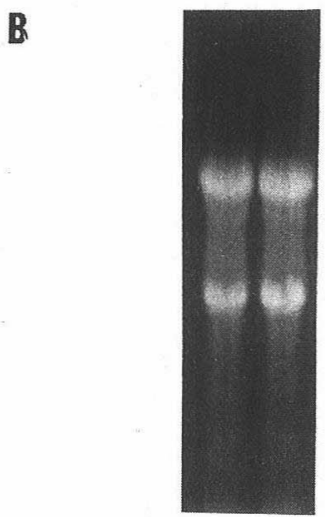

Fig. 1. Effect of vitamin $B_{6}$ deficiency on the level of cAST mRNA in the rat liver. (A) Northern blot analysis of total RNA from the liver of control (Con) and vitamin $\mathrm{B}_{6}$-deficient $\left(-\mathrm{B}_{6}\right)$ rats with the cAST cDNA probe. Twenty micrograms of total RNA were subjected to Northern blot analysis. The experiments shown are representative of five independent experiments. (B) Ethidium bromide staining of rRNA as an internal control of the amount of RNA loaded. 


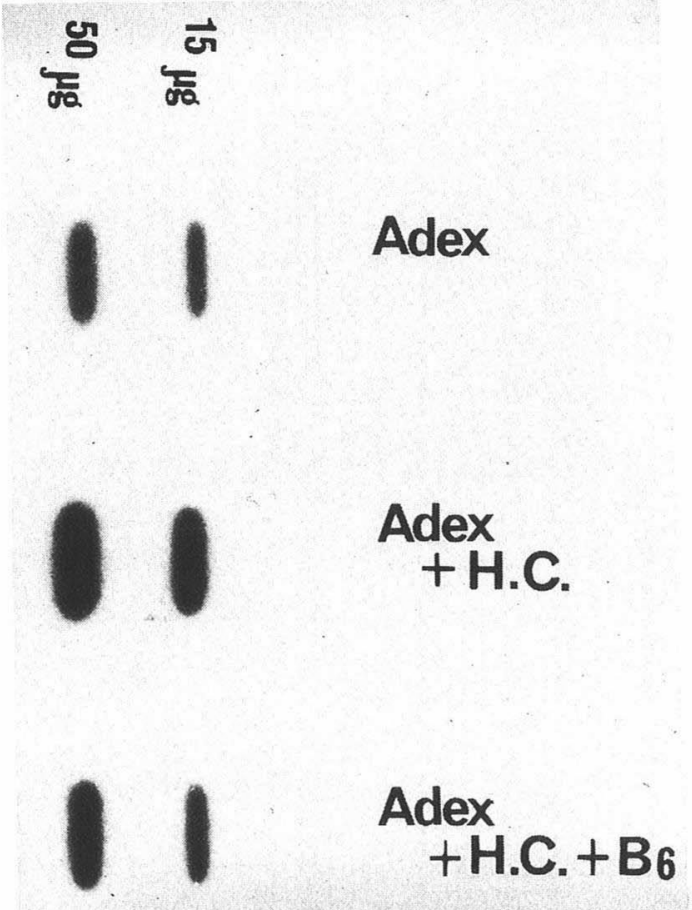

Fig. 2. Effect of hydrocortisone and pyridoxine treatments on the level of cAST mRNA in the liver of adrenalectomized vitamin $\mathbf{B}_{6}$-deficient rats. Slot blot analysis of total RNA from the livers of adrenalectomized (Adex), hydrocortisone-treated (H.C.) and pyridoxine-treated $\left(B_{6}\right)$ vitamin $B_{6}$-deficient rats with cAST cDNA probe. Two different quantities $(15$ and $50 \mu \mathrm{g})$ of total RNA were probed. The experiments shown are representative of five independent experiments.

Glucocorticoid-induction of cAST $m R N A$ is suppressed by vitamin $B_{6}$ administration We next examined the effects of glucocorticoid hormone and vitamin $B_{6}$ administration on the hepatic cAST mRNA level by slot blot analysis using adrenalectomized vitamin $\mathrm{B}_{6}$-deficient rats. Following hydrocortisone treatment, the cAST mRNA level increased significantly but the increase was suppressed by the combined treatment of hydrocortisone and pyridoxine (Fig. 2). Adrenalectomy alone did not affect the cAST mRNA level in the liver of vitamin $\mathrm{B}_{6}$-deficient rats (data not shown).

Binding activity of nuclear extract to glucocorticoid-responsive element in cAST gene is enhanced in vitamin $B_{6}$-deficiency

The analysis of the $5^{\prime}$ regulatory region of the rat cAST gene revealed several sequences showing homology to glucocorticoid-responsive elements. The sequence 

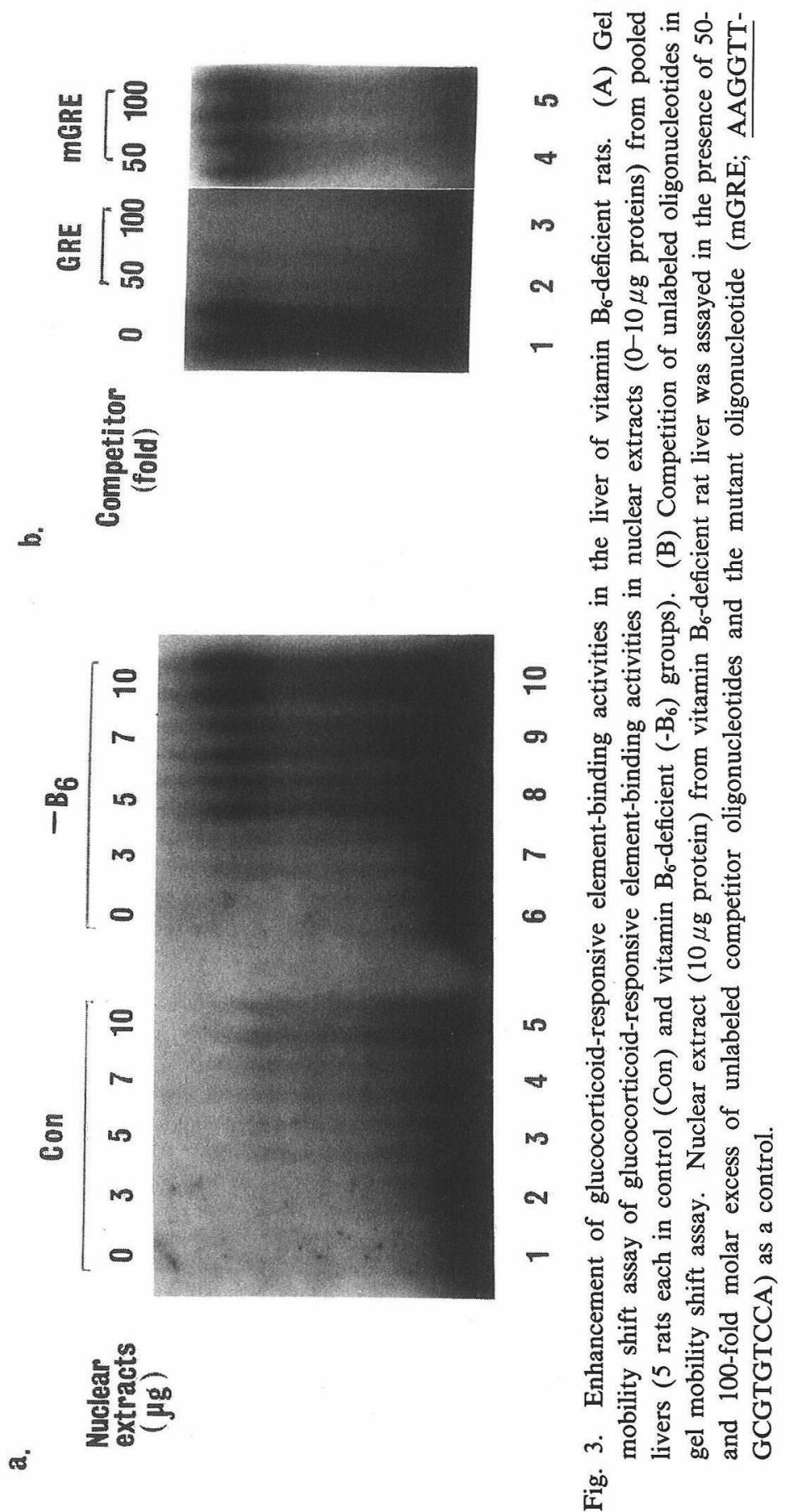
A

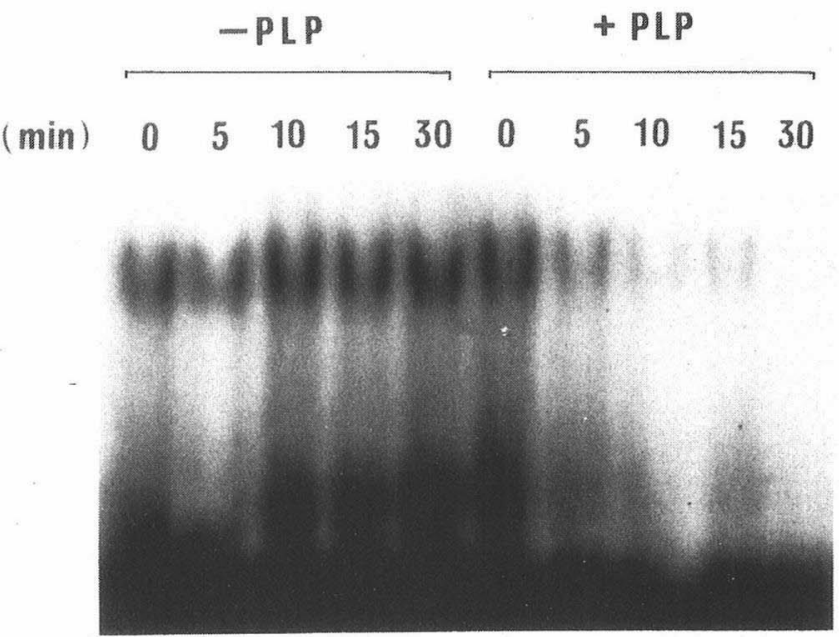

$\begin{array}{llllllllll}1 & 2 & 3 & 4 & 5 & 6 & 7 & 8 & 9 & 10\end{array}$

B
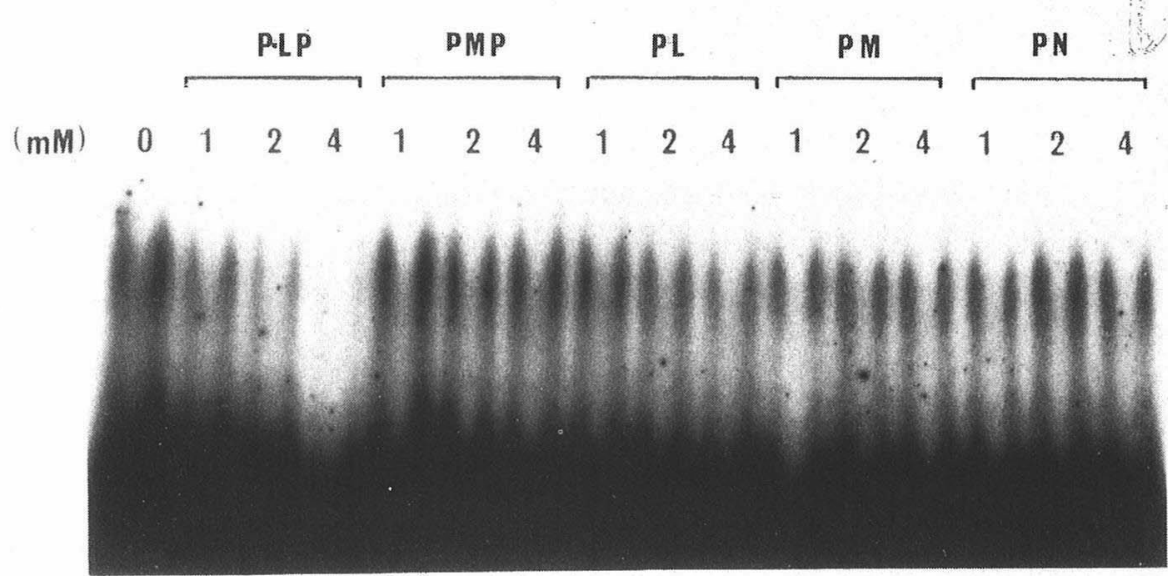

$\begin{array}{llllllllllllllll}1 & 2 & 3 & 4 & 5 & 6 & 7 & 8 & 9 & 10 & 11 & 12 & 13 & 14 & 15 & 16\end{array}$

Fig. 4. Effect of PLP and its congeners on the binding activity of nuclear extract to glucocorticoid-responsive element in vitro. (A) Time course of inactivation of the binding activity by PLP. Nuclear extract ( $10 \mu \mathrm{g}$ protein), prepared from the liver of vitamin $\mathrm{B}_{6}$-deficient rats, was preincubated in the binding buffer at $25^{\circ} \mathrm{C}$ in the absence or presence of $4 \mathrm{mM}$ PLP for the indicated times before the addition of ${ }^{32} \mathrm{P}$-labeled oligonucleotide probe. (B) Effect of PLP, pyridoxamine 5 -phosphate (PMP), pyridoxal (PL), pyridoxamine (PM) and pyridoxine (PN) on the binding activity. Nuclear extract ( $10 \mu \mathrm{g}$ protein), prepared from the liver of vitamin $\mathbf{B}_{6}$-deficient rats, was preincubated in the binding buffer for $30 \mathrm{~min}$ at $25^{\circ} \mathrm{C}$ in the presence of PLP and its congeners at the indicated concentrations before the addition of ${ }^{32} \mathrm{P}$-labeled oligonucleotide probe. 
with the highest homology was found at position -585 to -571 (GGTACAGCGTGTCCA) which differed by only one nucleotide from the consensus sequence (GGTACANNNTGTT/CCT; Ref 15) (12). We synthesized this oligonucleotide and assayed its binding activity with liver nuclear extract by gel mobility shift analysis. Figure 3 shows that the binding activity of nuclear extract, prepared from the liver of vitamin $\mathbf{B}_{6}$-deficient rats (Fig. 3a, lanes 6-10) to the oligonucleotide was far greater than that of the control (Fig. 3a, lanes 1-5). The sequence specificity of the bindings was verified by the addition of 50- to 100-fold molar excess of unlabeled competitor oligonucleotide (Fig. 3b, lanes 1-3). The result indicates that the DNA-binding activity of glucocorticoid receptor was greatly enhanced in the liver of vitamin-deficient rats.

PLP inhibits binding activity of nuclear extract to glucocorticoid-responsive element in vitro

To see if the lower DNA-binding activity of the nuclear extract, prepared from the control liver is due to direct interaction of the glucocorticoid receptor with vitamin $\mathrm{B}_{6}$, we examined the effect of PLP on the binding activity of nuclear extract in vitro. As seen in Fig. 4a, preincubation of nuclear extract from vitamin-deficient liver with PLP brought about a rapid and extensive decrease in the binding of the extract to the oligonucleotide sequence of the glucocorticoid-responsive element. Figure $4 \mathrm{~b}$ shows the effects of different concentrations of PLP and its congeners, pyridoxamine 5 '-phosphate, pyridoxal, pyridoxamine, and pyridoxine, on the binding activity of nuclear extract. At $1 \mathrm{~mm}$, only PLP was effective; the other congeners were not effective at concentrations up to $4 \mathrm{~mm}$. This observation indicates that both a phosphate and an aldehyde group are required for the inactivation.

\section{DISCUSSION}

We have reported previously that the rate of synthesis of cAST in the liver of vitamin $\mathbf{B}_{6}$-deficient rats is increased 3-fold, compared with the control rats fed the diet containing vitamin $\mathrm{B}_{6}$ ad libitum (16). We now found that the level of cAST mRNA in the liver of vitamin $B_{6}$-deficient rats is 7 -fold higher than that in the control rats, suggesting that the mechanism of cAST induction in vitamin $B_{6}$ deficiency is largely transcriptional.

Inasmuch as the rate of synthesis of cAST is increased in the liver of vitamin $B_{6}$-deficient rats, one would expect an increase in the steady-state level of cAST in the vitamin-deficient liver. However, our previous work has demonstrated that the level of immunochemically determined cAST protein in the liver of the deficient rats is essentially the same as that in the liver of control rats (17). This could occur if not only the rate of synthesis but also the rate of degradation of cAST in the liver were increased in vitamin $B_{6}$ deficiency. We have previously shown that the rate of degradation of cAST is indeed increased in vitamin $\mathrm{B}_{6}$ deficiency (18). We have 
further shown that the increased rate of degradation of cAST is due to an accelerated sequestration of the enzyme into lysosomes (19).

Glucocorticoid hormones have been shown to induce a variety of enzymes in the liver (20) and, in particular, a number of transaminases with different specificities. We have reported that CAST is induced in the liver of adrenalectomized vitamin $\mathrm{B}_{6}$-deficient rats by hydrocortisone and that the induction is suppressed by the administration of pyridoxine (8). Slot blot analysis of cAST mRNA in the present study shows that the hydrocortisone treatment increases the level of cAST mRNA and that the increase is prevented by the simultaneous administration of pyridoxine. On the other hand, we have already shown that the liver of rats treated with pyridoxine daily for 6 days had normal levels of PLP (8). The contents of serum corticosterone were also determined in the control and $\mathrm{B}_{6}$-deficient rats, but no significant difference was observed $(8)$. These observations indicate that changes in the rate of synthesis of cAST in the liver by glucocorticoid and vitamin $\mathrm{B}_{6}$ are regulated by the corresponding changes in the level of cAST mRNA. Glucocorticoid regulation of cAST mRNA levels in the liver of rats maintained on normal vitamin $\mathrm{B}_{6}$-containing diet has been described previously by Pave-Preux et al. (2).

Studies on the mechanism of glucocorticoid induction of a number of enzymes have shown that glucocorticoid receptor binds to the genes of these enzymes at glucocorticoid-responsive elements and increases their transcription. These sites have been found in a variety of genes regulated by glucocorticoids (21-23) and recent analysis of the $5^{\prime}$ regulatory region of rat cAST gene by Pave-Preux et al. (12) revealed several sequences showing homology to glucocorticoid-responsive elements. The sequence with the highest homology was found at position -585 to -571 (GGTACAGCGTGTCCA). To see if the elevation of the cAST mRNA level in the liver of vitamin $\mathbf{B}_{6}$-deficient rats is due to increased binding of glucocorticoid receptor to glucocorticoid-responsive elements, we performed a gel mobility shift assay using an oligonucleotide probe of the glucocorticoid-responsive element sequence described above. The assay showed that the binding activity of the liver extract from vitamin $\mathrm{B}_{6}$-deficient rats is clearly greater than that from the control rats, indicating that the DNA-binding activity of glucocorticoid receptor is indeed enhanced in vitamin $\mathrm{B}_{6}$ deficiency.

The presently observed inactivation of DNA-binding activity of the liver extract upon incubation in vitro with PLP suggests that the modulation of cAST gene expression by vitamin $\mathbf{B}_{6}$ status is due to direct interaction of glucocorticoid receptor with PLP. It is well-known that PLP is the coenzyme of several enzymes of amino acid metabolism. Apart from its role as the coenzyme, PLP has proven to be an effective inhibitor of many enzymes which have binding sites for phosphate-containing substrates or effectors including RNA polymerase $(24,25)$, reverse transcriptase (26), Escherichia coli DNA polymerase I (27), and animal cell DNA polymerase $(28,29)$. In all these cases, PLP is by far more effective than its congeners and PLP typically interacts with proteins by forming a Schiff base 
between its aldehyde group and the primary amino group, most commonly the $\varepsilon$-amino groups of lysine residues (30). Probably, the presently observed interaction of PLP with glucocorticoid receptor also involves Schiff base formation. Since PLP constitutes the major portion of vitamin $B_{6}$ vitamers in the rat liver (31), we propose that the intracellular level of PLP modulates the activities of glucocorticoid receptor in vivo.

A question may be raised as to how closely the PLP treatment in vitro approximates conditions in vivo. The millimolar concentrations of PLP and its analogues used in the in vitro experiments are about 100 times the levels found in vivo. These high concentrations were employed to show that only PLP was effective among all the $\mathrm{B}_{6}$ vitamers tested, but the rapidity of the PLP action on the DNA-binding activity of nuclear extract in vitro suggests that PLP may work at a considerably lower concentration. However, the determinations of the site(s) of PLP binding must wait until we construct an assay system using purified preparation of glucocorticoid receptor.

We have recently found that vitamin $B_{6}$ deficiency causes activation of RNA polymerase I and II, and brings about a general enhancement of gene expression in the rat liver, including such housekeeping genes like $\beta$-actin and glyceraldehyde-3phosphate dehydrogenase (32). This finding suggests that vitamin $\mathrm{B}_{6}$ influences gene expression in the liver, at least in part, by modulating the activity of RNA polymerase. However, the magnitude of the increase in the level of cAST mRNA in the present study is far greater than that which can be explained in terms of RNA polymerase activity.

Allgood and associates have shown that vitamin $\mathrm{B}_{6}$ modulates transcriptional activation by glucocorticoid receptor (6) as well as other members of the steroid hormone receptor superfamily (7) through a mechanism that does not involve alterations in hormone receptor concentration or ligand binding capacity. They have reported recently that modulation by vitamin $\mathrm{B}_{6}$ of glucocorticoid receptormediated gene expression requires transcription factors, such as nuclear factor 1 , in addition to the glucocorticoid receptor (33). The data presented here provide a molecular basis for the regulatory role of vitamin $\mathrm{B}_{6}$, demonstrating that PLP modulates the cAST gene expression by inactivating the binding activity of glucocorticoid receptor to glucocorticoid-responsive elements.

Note added in proof. We have recently found that pyridoxal 5 -phosphate also modulates the expression of albumin gene in rat liver by inactivating tissue-specific transcription factors such as HNF-1 and C/EBP in a similar manner to the glucocorticoid receptor (T. Oka et al., Biochem. $J$., in press). It thus appears that the gene-regulatory action of pyridoxal 5 -phosphate is not limited to glucocorticoid receptor but involves many other DNA-binding proteins.

This research was supported in part by a Grant-in-Aid for Scientific Research (No. 06680618) from the Ministry of Education, Science and Culture of Japan. 


\section{REFERENCES}

1) Braunstein, A. E., and Snell, E. E. (1985): Transamination and transaminases, in Transaminase, ed. by Christen, P., and Metzler, D. E., John Wiley and Sons, New York, pp. 2-35.

2) Pave-Preux, M., Ferry, N., Bouguet, J., Hanoune, J., and Barouki, R. (1988): Nucleotide sequence and glucocorticoid regulation of the mRNAs for the isoenzymes of rat aspartate aminotransferase. J. Biol. Chem., 263, 17459-17466.

3) Cake, M. H., DiSorbo, D. M., and Litwack, G. (1978): Effect of pyridoxal phosphate on the DNA binding site of activated hepatic glucocorticoid receptor. J. Biol. Chem., 253, 4886-4891.

4) DiSorbo, D. M., and Litwack, G. (1981): Changes in the intracellular levels of pyridoxal $5^{\prime}$-phosphate affect the induction of tyrosine aminotransferase by glucocorticoids. Biochem. Biophys. Res. Commun., 99, 1203-1208.

5) Majumder, P. K., Joshi, J. B., and Banerjee, M. R. (1983): Correlation between nuclear glucocorticoid receptor levels and casein gene expression in murine mammary gland in vitro. J. Biol. Chem., 258, 6793-6798.

6) Allgood, V. E., Powell-Oliver, F. E., and Cidlowski, J. A. (1990): Vitamin B influences glucocorticoid receptor-dependent gene expression. J. Biol. Chem., 265, 12424-12433.

7) Allgood, V. E., and Cidlowski, J. A. (1992): Vitamin $B_{6}$ modulates transcriptional activation by multiple members of the steroid hormone receptor superfamily. J. Biol. Chem., 267, 3819-3824.

8) Kondo, T., and Okada, M. (1985): Effect of pyridoxine administration on the induction of cytosolic aspartate aminotransferase in the liver of rats treated with hydrocortisone. J. Nutr. Sci. Vitaminol., 31, 509-517.

9) Okada, M., and Suzuki, K. (1974): Amino acid metabolism in rat fed a high protein diet without pyridoxine. J. Nutr., 104, 287-293.

10) Oka, T., Sasakawa, T., Komori, N., Miyamoto, K., Suzuki, I., Sassa, T., and Natori, Y. (1993): Developmental changes in the expression of HMG 2a protein. FEBS Lett., 316, 20-22.

11) Dignam, J. D., Levovitz, R. M., and Roeder, R. G. (1983): Accurate transcription initiation by RNA polymerase II in a soluble extract from isolated mammalian nuclei. Nucl. Acids Res., 11, 1475-1489.

12) Pave-Preux, M., Aggerbeck, M., Veyssier, C., Bousquet-Lemercier, B., Hanoune, J., and Barouki, R. (1990): Hormonal discrimination among transcription start sites of aspartate aminotransferase. J. Biol. Chem., 265, 4444-4448.

13) Chodosh, L. A. (1990): in Current Protocols in Molecular Biology, ed. by Ausubel, F. M., Brent, R., Kingston, R. E., Moore, D. D., Seidman, J. D., Smith, J. A., and Struhl, K., John Wiley and Sons, New York, pp. 12.2.1.-12.2.10.

14) Itoh, R., and Okada, M. (1973): Effect of dietary protein level on pyridoxal content in tissues and excretion of pyridoxic acid into urine in normal and pyridoxine-deficient rat. J. Nutr. Sci. Vitaminol., 19, 523-528.

15) Beato, M. (1989): Gene regulation by steroid hormones. Cell, 56, 335-344.

16) Kondo, T., Nagata, K., Shibuya, M., and Okada, M. (1982): Effect of pyridoxine- 
deficiency on the synthesis of aspartate aminotransferase in rat liver and muscle in vivo. J. Biochem., 92, 1087-1091.

17) Shibuya, M., Nagata, K., and Okada, M. (1982): Effect of pyridoxine-deficiency on activities and amounts of aspartate aminotransferase isozymes in rat tissues. $J$. Biochem., 92, 1399-1042.

18) Shibuya, M., and Okada, M. (1986): Effect of pyridoxine-deficiency on the turnover of aspartate aminotransferase isozymes in rat liver. J. Biochem., 99, 939-944.

19) Sato, A., Nagai, M., Tagami, A., Natori, Y., and Okada, M. (1991): Effect of pyridoxine-deficiency on degradation of cytosolic aspartate aminotransferase in rat liver lysosomes. J. Nutr. Sci. Vitaminol., 37, 419-424.

20) Exton, J. H. (1979): Regulation of gluconeogenesis by glucocorticoids, in Glucocorticoid Hormone Action, ed. by Baxter, J. D., and Rousseau, G. G., Springer-Verlag, New York, pp. 535-546.

21) Payvar, F., Wrange, O., Carlstedt-Duke, J., Okret, S., Gustafsson, J. A., and Yamamoto, K. R. (1981): Purified glucocorticoid receptors bind selectively in vitro to a cloned DNA fragment whose transcription is regulated by glucocorticoids in vivo. Proc. Natl. Acad. Sci. U.S.A., 78, 6628-6632.

22) Strahle, U., Klocj, G., and Schutz, G. (1987): A DNA sequence of 15 base pairs is sufficient to mediate both glucocorticoid and progesterone induction of gene expression. Proc. Natl. Acad. Sci. U.S.A., 84, 7871-7875.

23) Miksicek, R., Heber, A., Schmid, W., Danesch, U., Posseckert, G., Beato, M., and Schutz, G. (1986): Glucocorticoid responsiveness of the transcriptional enhancer of Moloney murine sarcoma virus. Cell, 46, 283-290.

24) Venegas, A., Martial, J., and Valenzuela, P. (1973): Active site-directed inhibition of E. coli DNA-dependent RNA polymerase by pyridoxal 5'-phosphate. Biochem. Biophys. Res. Commun., 55, 1053-1059.

25) Martial, J., Zardivar, J., Bull, P., Venegas, A., and Valenzuela, P. (1975): Inactivation of rat liver RNA polymerase I and II and yeast RNA polymerase I by pyridoxal 5'phosphate. Evidence for the participation of lysyl residue at the active site. Biochemistry, 14, 4907-4911.

26) Basu, A., Tirumalai, R. S., and Modak, M. J. (1989): Substrate binding in human immunodeficiency virus reverse transcriptase. J. Biol. Chem., 264, 8746-8752.

27) Basu, A., and Modak, M. J. (1987): Identification and amino acid sequence of the deoxynucleoside triphosphate binding site in Escherichia coli DNA polymerase I. Biochemistry, 26, 1704-1709.

28) Modak, M. J. (1976): Observation of the pyridoxal 5'-phosphate inhibition of DNA polymerase I. Biochemistry, 15, 3620-3626.

29) Diffley, J. F. X. (1988): Affinity labeling the DNA polymerase $\alpha$ complex. 1. Pyridoxal 5 '-phosphate inhibition of DNA polymerase $\alpha$ complex from Drosophila melanogaster embryos. J. Biol. Chem., 263, 14669-14677.

30) Fischer, E. H., Kent, A. B., Snyder, E. R., and Krebs, E. G. (1958): The reaction of sodium borohydrate with muscle phosphorylase. J. Am. Chem. Soc., 80, 2906-2907.

31) Goburn, S. P., Mahuren, J. D., Kennedy, M. S., Schaltenbrand, W. E., Sampson, D. A., O'Connor, D. K., Snyder, D. L., and Wostmann, B. S. (1988): B 6 vitamer content of rat tissues measured by isotope tracer and chromatographic methods. BioFactors, $\mathbf{1}$, $307-312$. 
32) Oka, T., Komori, N., Kuwahata, M., Sassa, T., Suzuki, I., Okada, M., and Natori, Y. (1993): Vitamin $B_{6}$ deficiency causes activation of RNA polymerase and general enhancement of gene expression in rat liver. FEBS Lett., 331, 162-164.

33) Allgood, V. E., Oakley, R. H., and Cidlowski, J. A. (1993): Modulation by vitamin B $_{6}$ of glucocorticoid receptor-mediated gene expression requires transcription factors in addition to the glucocorticoid receptor. J. Biol. Chem., 268, 20870-20876. 